\title{
Safety considerations during prescription of non-steroidal anti- inflammatory drugs (NSAIDs), through a review of systematic reviews
}

\section{Consideraciones de seguridad en la prescripción de medicamentos antiinflamatorios no esteroideos (AINEs), a través de una revisión de revisiones sistemáticas}

https://doi.org/10.23938/ASSN.0965

\author{
A. Olry de Labry Lima ${ }^{1,2,3}$, E. Salamanca-Fernández ${ }^{2,3,4}$, E.J. Alegre del Rey ${ }^{5}$, \\ A. Matas Hoces ${ }^{1,6}$, M.Á. González Vera ${ }^{7}$, C. Bermúdez Tamayo ${ }^{1,2,3}$
}

\begin{abstract}
Non-steroidal anti-inflammatory drugs (NSAIDs) are among the most widely used drugs worldwide. This makes it necessary to carry out a comprehensive synthesis of the available evidence on the safe and adequate prescription of NSAIDs in patients with cardiovascular disease, chronic kidney disease, hypertension, heart failure or liver cirrhosis and in general population. For this, a review of systematic reviews was carried out. Data extraction and analysis were performed independently by two reviewers and a narrative synthesis of the results was carried out. The use of NSAIDs is associated with a significantly higher probability of hepatotoxicity and kidney damage, as well as increased risk of exacerbation of heart failure. Taking into account the increased cardiovascular, liver and kidney risk, the prescription of NSAIDs should be carried out with caution, considering the treatment duration and the patient's situation. For this reason, patients should be informed about their possible health consequences as well as ensuring adequate monitoring of them.
\end{abstract}

Keywords. NSAIDs. Cardiovascular disease. Hypertension. Umbrella review.

\begin{abstract}
RESUMEN
Los medicamentos antiinflamatorios no esteroideos (AINEs) se encuentran entre los medicamentos más consumidos mundialmente. Esto hace necesario realizar una síntesis amplia de la evidencia disponible sobre la prescripción segura y adecuada de AINEs en pacientes con enfermedad cardiovascular, enfermedad renal crónica, hipertensión, insuficiencia cardíaca o cirrosis hepática y en población general. Para ello se ha realizado una revisión de revisiones sistemáticas. El uso de AINEs se asoció a una probabilidad significativamente mayor de hepatotoxicidad y daño renal y un mayor riesgo de exacerbación de la insuficiencia cardíaca. Teniendo en cuenta el aumento del riesgo cardiovascular, hepático y renal, la prescripción de AINEs debe realizarse con cautela, considerando la duración del tratamiento y la situación del paciente. Por ello, se debe informar a los pacientes sobre sus posibles consecuencias para la salud así como garantizar un seguimiento adecuado de los mismos.
\end{abstract}

Palabras clave. AINEs. Enfermedad cardiovascular. Hipertensión. Revisión paraguas.
1. Andalusian School of Public Health (EASP). Campus Universitario de Cartuja. Granada. Spain.

2. CIBER of Epidemiology and Public Health (CIBERESP). Spain.

3. Instituto de Investigación Biosanitaria de Granada. Granada. Spain.

4. Radiology and Physical Medicine Department. University of Granada. Granada. Spain.

5. Pharmacy Service. Hospital Universitario Puerto Real. Cádiz. Spain.

6. CADIME: Andalusian Medicine Information Center. Granada. Spain.

7. Farmacia del Puente. Pinos Puente. Granada. Spain.

\section{Corresponding author:}

Elena Salamanca-Fernández

Radiology and Physical Medicine Department

University of Granada

Campus Universitario de Cartuja

C/ Cuesta del Observatorio, 4

18080 Granada

Spain

E-mail: esalamanca@ugr.es

\section{Funding:}

This study was financed by Consejería de Salud de la Junta de Andalucía (Exp. PIN-0155-2017)

Received: September, 11, 2020

Revised: December, 10, 2020

Accepted: April, 26, 2021 


\section{BACKGROUND}

Nonsteroidal anti-inflammatory drugs (NSAIDs) are a heterogeneous group of drugs that are among the most widely used due to their anti-inflammatory, analgesic and antipyretic action ${ }^{1}$. The most commonly used drug is ibuprofen, followed by naproxen ${ }^{2}$. Patients with chronic pain are one of the most frequent users of NSAIDs. The World Health Organization (WHO) introduced the analgesic ladder for cancer pain $^{3}$, which later extended to chronic non-malignant pain. In this scale, NSAIDs are described as the main option for the management of pain in the first step of the ladder, and as a complementary medication in the second and third steps, adding weak or strong opioids and adjuvants ${ }^{4}$.

It must be taken into account that NSAIDs are considered inappropriate in $25 \%$ of patients, and in $50 \%$ in patients aged over 65 ; the probability that the prescription is inappropriate is five times higher in this age group ${ }^{5}$. Several clinical practice guidelines warn about prescribing NSAIDs to patients with cardiovascular disease, chronic kidney disease, hypertension, heart failure and cirrhosis; and recommend caution if the prescription of NSAIDs is necessary ${ }^{1,6}$. The authors have not found in the scientific literature a document that synthesizes the evidence on the different aspects of the safety of NSAIDs.

For all that, this study aims at providing a wide synthesis of the available evidence regarding the safety of NSAIDs in patients with cardiovascular disease, chronic kidney disease, hypertension, heart failure, or liver cirrhosis.

\section{METHODS}

An umbrella review (review of existing systematic reviews and meta-analyses) was carried out ${ }^{7}$. The PICO model was followed for this review:

- P (population): patients with cardiovascular comorbidities or at risk of suffering complications, and general population

- I (intervention): use of NSAIDs
- C (comparison): any

- O (outcome): safety.

The databases consulted were Medline, Embase, Scopus and the Cochrane Library. The search was complemented with the following resources: Google Scholar and the Spanish Network of Health Technology Assessment Agencies ${ }^{8}$. In addition, the reference lists of the identified articles were examined. The search strategy adopted for the different databases was validated by a librarian specialized in Public Health (Appendix 1) and was updated to 1st July, 2019. To maximize search sensitivity, two searches were carried out in parallel, with and without review filter (SIGN). The literature search was complemented by other databases and grey literature. The writing process of this umbrella review was done following an adaptation of the guide published by Bougioukas et al. ${ }^{9}$.

Inclusion criteria: systematic reviews (SR) and meta-analyses offering relevant information concerning the object of the study, reviews written in English or Spanish, with no publication date restrictions; when two reviews with similar objectives were located, the most recently published one was selected. Exclusion criteria: original article, editorial or commentary, animal/laboratory study, or NSAID exposure not clear.

References were stored in Mendeley reference manager and reviewed to identify potentially relevant documents. Two reviewers independently screened titles (AOL and ESF) and abstracts to determine whether the documents met the inclusion criteria; those that met the criteria were kept as potential documents (first screening step) (Appendix 2). Additional references were obtained after screening by cross-checking the references of previously identified documents. Both reviewers then independently evaluated the papers selected for full-text examination (second screening step). A third independent reviewer (CBT) resolved any discrepancies during both screening processes. The analysis of the content was performed according to categories related to the different predefined populations. Finally, a narrative synthesis was done.

A measurement tool to assess systematic reviews (AMSTAR) ${ }^{10}$ was chosen to 
assess the quality of the reviews included in our umbrella review. AMSTAR was developed to evaluate SR of randomized trials and allows a more detailed evaluation of SR that also include non-randomized studies of health interventions, which are increasingly incorporated into SR.

\section{RESULTS}

The search identified a total of 1,406 references (Fig. 1). After a first reading of titles and abstracts, a total of 103 reviews were selected to the next step for full-text screening to ensure articles met all eligibility criteria. Finally, 22 articles were included in this overview (Table 1). The authors reviewed the possibility of performing a meta-analysis with the results of the articles included in this review; however, it was not possible due to the differences in the populations of the included reviews.

\section{Patients with risk of hepatotoxicity}

Sriuttha et al. ${ }^{11}$ included 18 randomised controlled trials (RCT) ( $\mathrm{n}=45,705$ subjects) that evaluated the risk of hepato- toxicity associated with NSAIDs. Length of the studies ranged from four weeks or less for four studies (22.2\%), six weeks for one study (5.6\%), 12 weeks for six studies $(33.3 \%)$, and 16 weeks or longer for seven studies (38.9\%). Indication of NSAIDs corresponded to osteoarthritis (13 studies) and for rheumatoid arthritis (five studies). A total of eight studies describing the use of three NSAIDs (celecoxib, etoricoxib and diclofenac) reported clinically significant hepatotoxicity, with diclofenac showing the highest proportion of hepatotoxic events (range $0.015 \times 10^{-2}-4.3 \times 10^{-2}$, followed by celecoxib (range $0.13 \times 10^{-2}-0.38 \times 10^{-2}$ ), and etoricoxib (range $0.005 \times 10^{-2}-0.930 \times 10^{-2}$ ).

\section{Patients with risk of chronic kidney disease (CKD)}

Nderitu et al. review ${ }^{12}$ included seven studies, of which three were included in the meta-analysis. This study found that the use of NSAIDs in regular doses did not significantly affect the risk of accelerated progression of CKD (OR $=0.96 ; 95 \% \mathrm{CI}$ : 0.86-1.07), but the use of high doses of NSAIDs increased the risk of accelerating the progression of $\mathrm{CKD}(\mathrm{OR}=1.26$; 95\%CI: 1.06-1.50).

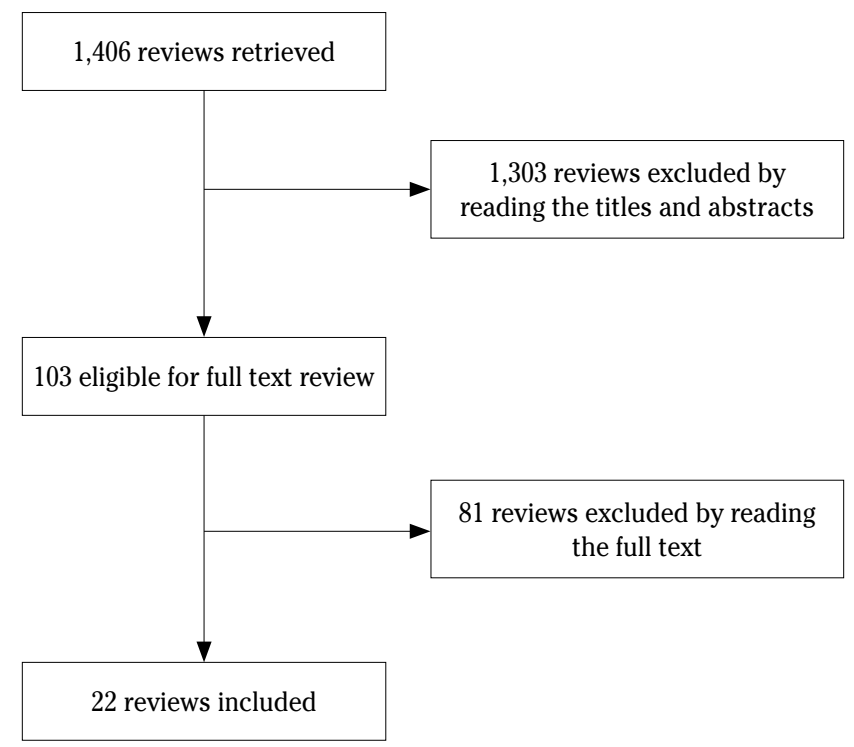

Figure 1. Flow diagram of the review included in the study. 
Table 1. Characteristics of the systematic reviews and meta-analysis included in this umbrella review

\begin{tabular}{|c|c|}
\hline Authors & Studies included in the review \\
\hline Sriuttha et al. ${ }^{11}$ & 18 RCT (45,705 participants) \\
\hline Nderitu et al. ${ }^{12}$ & 7 studies: $5 \mathrm{CO}, 1 \mathrm{CC}, 1 \mathrm{CS}$ \\
\hline Zhang et al..$^{13}$ & $\begin{array}{l}15 \text { studies: } \\
\text { - } 10 \text { studies with general population }(\mathrm{n}=1,609,136): 5 \mathrm{nCC}, 5 \mathrm{CC} \\
-5 \text { studies with chronic renal failure patients }(\mathrm{n}=106,681), \mathrm{CC}\end{array}$ \\
\hline Asghar et al. ${ }^{14}$ & 19 studies: $12 \mathrm{CC}, 4 \mathrm{CO}, 3 \mathrm{RCT}$ \\
\hline Yaxley et al. ${ }^{15}$ & 9 studies: $5 \mathrm{CO}, 4 \mathrm{CC}(12,418$ participants and 23,877 controls $)$ \\
\hline Villa et al. ${ }^{16}$ & 19 studies \\
\hline Ungprasert et al. ${ }^{17}$ & 7 studies: 4 CC, 3 CO $(7,543,805$ participants $)$ \\
\hline Liu et al. ${ }^{18}$ & 5 studies: 3 CC, 2 CO \\
\hline Seshasai et al..$^{19}$ & 9 RCT (over 100,000 participants) \\
\hline Whitlock et al. ${ }^{20}$ & 7 studies: 6 CO, 1 RCT \\
\hline Boulakh et al. ${ }^{21}$ & 14 studies: 2 dbRT, 10 CO, 2 CC \\
\hline Ungprasert et al. ${ }^{22}$ & 6 studies: $3 \mathrm{CC}, 3 \mathrm{CO}$ \\
\hline García Rodríguez et al. ${ }^{23}$ & $4 \mathrm{CO}, 2 \mathrm{nCC}$ \\
\hline Salvo et al. $^{24}$ & $29 \mathrm{MA}$ \\
\hline Scott et al. ${ }^{25}$ & 21 studies: 5 CC, 2 CO, 12 RCT \\
\hline Varas-Lorenzo et al. ${ }^{26}$ & 25 studies: $8 \mathrm{CO}, 14 \mathrm{nCC}, 3 \mathrm{CC}$ \\
\hline McGettigan et al. ${ }^{27}$ & $\begin{array}{l}\text { 51 studies: } \\
-30 \text { CC }(184,946 \text { cardiovascular events }) \\
-21 \text { CO }\left(2.7 \times 10^{6} \text { exposed individuals }\right)\end{array}$ \\
\hline Mackenzie et al. ${ }^{28}$ & $17 \mathrm{RCT}$ \\
\hline Major et al. ${ }^{29}$ & 3 clinical trials (4,468 participants and 16,740 person-years of follow-up) \\
\hline Luni et al. ${ }^{30}$ & 6 studies: $1 \mathrm{CO}, 5 \mathrm{CC}$ \\
\hline Lee et $a l^{31}$ & $4 \mathrm{RCT}$ \\
\hline Bem et al..$^{32}$ & 28 controlled studies \\
\hline
\end{tabular}

RCT: randomized clinical trial; CO: cohort; CC: case-control; CS: cross-sectional; nCC: nested case-control in a cohort; dbRT: randomized double-blind trial; MA: meta-analysis.

The second review ${ }^{13}$ examined the risk of acute kidney injury (AKI) - defined by: change in estimated glomerular filtration rate (eGFR) or creatinine clearance $(\mathrm{CrCl})$ or serum creatinine ( $\mathrm{SCr}$ )) associated with NSAIDs in the general population and in those with pre-existing CKD. This review included 10 articles targeting the general population $(1,609,136$ participants), of which were performed with patients with chronic renal failure $(n=106,681)$. Regarding the design, five were case-control studies and the rest were nested case-control studies. Eight of the 10 studies targeting the general population showed a significant association between exposure to NSAIDs and kidney damage. The meta-analysis showed an $\mathrm{OR}=1.73$ (95\%CI: 1.44-2.07), although a high heterogeneity was found $\left(\mathrm{I}_{2}=89 \%\right.$, p
$<0.001)$. In the case of patients with kidney disease, four of the five studies showed a significant association $(\mathrm{OR}=1.63 ; 95 \% \mathrm{CI}$ : $1.22-2.19 ; \mathrm{I}_{2}=71 \%$ ). In the subgroup analysis, it was found that a greater cyclooxygenase-2 (COX-2) selectivity was associated with a lower risk of AKI. Similar results were shown in the review of Asghar et al. ${ }^{14}$, which demonstrated that meloxicam did not elevate renal risk $(\mathrm{OR}=0.99 ; 95 \% \mathrm{CI}$ : 0.72-1.35) in general population.

In order to assess the relation between NSAIDs and analgesic nephropathy, a total of nine studies were included $(12,418$ participants and 23,877 controls) in Yaxley et al. review $^{15}$, and only one of the nine included studies found a relation between the chronic use of NSAID and analgesic nephropathy (OR=2.1; 95\%CI: 1.1-4.1). 


\section{Patients on antihypertensive treatment}

A review to assess the interaction between antihypertensives and NSAIDs ( $n=19$ studies) found 21 pharmacodynamic interactions, which according to their clinical relevance were classified in level-2 high risk (76.2\%) and level-3 medium risk (23.8\%). Results showed that some NSAIDs might attenuate the effectiveness of antihypertensive treatment, especially with angiotensin-converting enzyme inhibitors, diuretics, beta-blockers and angiotensin receptor blockers. There was no evidence of effect modification of calcium channel antagonists, especially dihydropyridine, by concurrent use of NSAIDs ${ }^{16}$.

\section{Patients with cardiovascular disease (CVD) - Primary prevention}

Ungprasert et al. ${ }^{17}$ reviewed the association between the use of NSAIDs and the incidence of heart failure ( $\mathrm{n}=7$ studies with $7,543,805$ participants). A significantly higher risk of developing heart failure was found with the use of NSAIDs (RR=1.17; 95\%CI: $1.01-1.36 ; \mathrm{I}_{2}=53 \%$ ). When performing the subgroup analysis, a higher risk of heart failure was found among the users of conventional NSAIDs (RR=1.35; 95\%CI: 1.15-1.57; $\mathrm{I}_{2}=0 \%$ ), but not among COX-2 specific inhibitors (COXIB) users (RR=1.03; 95\%CI: 0.92-1.16; $\mathrm{I}_{2}=0 \%$ ). The use of NSAIDs ${ }^{18}$, excluding aspirin, was associated with a $12 \%$ increased risk for atrial fibrillation $(\mathrm{RR}=1.12$; $95 \% \mathrm{CI}$ : 1.06 $1.18 ; \mathrm{I}_{2}=65 \%$ ) in five studies (three case-controls and two cohorts). Selective NSAIDs showed an increased risk of atrial fibrillation $(\mathrm{RR}=1.24 ;$ 95\%CI: 1.18-1.30).

Another systematic review ${ }^{19}$, involving over 100,000 participants and with a mean follow-up of 6.0 years, concluded that aspirin treatment reduced total CVD events (OR=0.90; 95\%CI: $0.85-0.96 ; \quad \mathrm{NNT}=120)$, driven primarily by reductions in non-fatal myocardial infarction $(\mathrm{OR}=0.80 ; 95 \% \mathrm{CI}$ : $0.67-0.96$; NNT $=162$ ), and no significant reduction was found in CVD death (OR= 0.99; 95\%CI: 0.85-1.15). In secondary prevention, this review found that the aspirin in prophy- lactic treatment does not lead to reductions in cardiovascular death.

With regard to the use of aspirin, another SR concluded that an intervention of very low-dose aspirin ( $\leq 100 \mathrm{mg}$ daily or every other day) could increase haemorrhagic stroke risk although results are not statistically significant (OR=1.27; 95\%CI: 0.96-1.68) ${ }^{20}$.

\section{Patients with CVD - Secondary prevention}

Regarding population with myocardial infarction, Boulakh et al. ${ }^{21}$ included a total of 14 articles, with a follow-up between 30 days and 15 years. This review showed a clear relationship between the use of NSAIDs and re-infarction and death in patients with previous myocardial infarction. Ten of the included studies analysed re-infarction and death and provided evidence of a clear relationship between the use of NSAIDs and re-infarction and death in patients with previous myocardial infarction, being the risk higher with celecoxib, ibuprofen and diclofenac than with naproxen. Naproxen showed the lowest risk of cardiovascular death: in one study the HR was 1.27 (95\%CI: 1.01-1.59) and in other they found no association to death or recurrent infarction when the patients were treated with naproxen and ibuprofen.

In relation to heart failure, the review of Ungprasert et $a l_{.}^{22}$ found that in patients with heart failure, the use of conventional NSAIDs was associated with an increased risk of exacerbation of heart failure ( $\mathrm{RR}=1.39$; 95\%CI: $1.20-1.62)$. In concordance with these findings, Liu et al. ${ }^{18}$ found an increased risk for atrial fibrillation $(\mathrm{RR}=1.82$; 95\% $\mathrm{CI}$ : $1.42-2.32)$ in patients under treatment with NSAIDs. Patients with CKD also showed an increased risk for atrial fibrillation ( $\mathrm{RR}=1.58$; 95\%CI: 1.34-1.85).

\section{Patients with CVD - General population}

SR by García-Rodríguez et al. ${ }^{23}$ included six studies with different proportions of patients in secondary prevention. The review 
concluded that the overall effect of NSAIDs for fatal and non-fatal myocardial infarction was $\mathrm{RR}=1.21$ (95\%CI: 1.07-1.37), being the risk for non-fatal myocardial infarction higher than the risk for fatal myocardial infarction $(\mathrm{RR}=1.30 ; 95 \% \mathrm{CI}$ : $1.20-1.41 \mathrm{vs}$. $\mathrm{RR}=1.02 ; 95 \% \mathrm{CI}: 0.89-1.17$ ).

To estimate incidence rates for cardiovascular adverse events associated with the use of NSAIDs, a total of 29 meta-analyses were analysed by Salvo et al. ${ }^{24}$, providing 109 incidence rates. Cumulative incidence rates for myocardial infarction ranged from 0.12 $1.35 \%$ for celecoxib, $0.24-0.66 \%$ for etoricoxib, $0.09-0.37 \%$ for lumiracoxib, $0.30-0.89 \%$ for rofecoxib, and $0.11-0.61 \%$ for valdecoxib; there was a single estimate for parecoxib/ valdecoxib combination ( $0.58 \%)$. Moreover, cumulative incidence rates for stroke ranged from 0.02 to $0.79 \%$ for celecoxib and from 0.06 to $0.34 \%$ for lumiracoxib; there was a single estimate for rofecoxib $(0.12 \%)$ and for valdecoxib $(0.18 \%)$.

Scott et al. ${ }^{25}$ concluded that NSAIDs increased the risk of heart failure by $30-100 \%$. The absolute risk is small; less than one patient developed heart failure attributable to NSAIDs per hundred patient-years of treatment. These risks were relatively small and similar with conventional NSAIDs and COXIBs (OR $=1.14$; 95\%CI: 0.85-1.53). The risk of heart failure in patients receiving NSAIDs was higher in those with pre-existing heart failure.

Another SR that assessed the risk of acute myocardial infarction (AMI) associated with the use of individual NSAIDs in 25 studies (100,000 AMI events) ${ }^{26}$, included low-medium to high risk patients according to the prior history of myocardial infarction or coronary heart disease. There were no statistically significant differences of AMI ranged from naproxen, followed by celecoxib and ibuprofen; while an increased risk was shown for indomethacin $(\mathrm{RR}=1.40$; 95\%CI: 1.21-1.62), etodolac $(\mathrm{RR}=1.55$; 95\%CI: $1.16-2.06)$, and etoricoxib $(\mathrm{RR}=1.97$; 95\%CI: 1.35-2.89). Furthermore, except for naproxen, a higher risk was associated with higher doses and in people with prior history of coronary heart disease, even for short-time ( $\leq 3$ months) use of the NSAID.
The review conducted by McGettigan et $a .^{27}$, including RCTs and observational studies (51 papers), reached similar results.

The review published by Mackenzie et $a l .{ }^{28}$ suggested that there were no significant differences in cardiovascular outcomes between lumiracoxib and placebo or between lumiracoxib and other NSAIDs in patients with osteoarthritis. Accordingly, Asghar et al. ${ }^{14}$ (with 19 included studies: 12 case-controls, four cohorts and three RCTs) showed that meloxicam was associated with a low increase in composite of vascular and myocardial risk $(\mathrm{OR}=1.14 ; 95 \% \mathrm{CI}$ : 1.04-1.25), which was mainly vascular in nature $(\mathrm{OR}=1.35 ; 95 \% \mathrm{CI}$ : $1.18-1.55)$ as it did not elevate the risk of myocardial infarction (OR = 1.13; 95\%CI: 0.98-1.32).

Major et al. ${ }^{29}$ included three trials with 4,468 participants and 16,740 person-years of follow-up. The review concluded that aspirin did not achieve significant reductions in the risk of major cardiovascular events $\left(\mathrm{RR}=0.92\right.$; 95\%CI: $\left.0.49-1.73, \mathrm{I}_{2}=71 \%\right)$ or mortality (RR=0.74; $95 \% \mathrm{CI}: 0.55-1.00 ; \mathrm{I}_{2}=0 \%$ ) compared to the control group which was receiving placebo. Another SR including six observational studies ${ }^{30}$ concluded that there was no difference in major adverse cardiovascular events with planned discontinuation of aspirin (OR $=1.17 ; 95 \% \mathrm{CI}$ : $\left.0.76-1.81 ; \mathrm{I}_{2}=55 \%\right) . \mathrm{A} \mathrm{SR}^{31}$ that included RCTs comparing warfarin and aspirin, carried out in patients with heart failure and normal sinus rhythm, concluded that there were no significant differences in the deathstroke endpoint $(\mathrm{RR}=0.94 ; 95 \% \mathrm{CI}$ : 0.84-1.06; $\mathrm{p}=0.31)$, or death by any cause $(\mathrm{RR}=1.01$; 95\%CI: 0.89-1.14; $\mathrm{p}=0.89$ ) between warfarin and aspirin. On the contrary, the use of warfarin was associated with a lower risk of any stroke $(\mathrm{RR}=0.56 ; 95 \% \mathrm{CI}$ : 0.38-0.82, $\mathrm{p}=0.003$ ) and ischemic stroke ( $\mathrm{RR}=0.45$; $95 \% \mathrm{CI}$ : 0.24 $0.86, \mathrm{p}=0.02$ ) compared to aspirin.

Finally, a review ${ }^{32}$ assessed the evidence on the effects of different aspirin regimens in terms of timing (chronotherapy) or frequency of dosing in the prevention of cardiovascular disease. In general, the lack of significant differences was highlighted in both primary and secondary prevention to evaluate the evidence. 


\section{Risk of bias in the studies included}

The evaluation of methodological quality of the studies included in this review by the AMSTAR scale yielded heterogeneous risk of bias (Table 2). The. The quality of the re- view was critically low for 12 of the included reviews (54.5\%). In the rest of the cases the quality was low. The issues less addressed were To provide a list of excluded studies and Justify the exclusions (critical) and the sources of funding for the studies included in the review.

Table 2. AMSTAR 2 assessment of the included systematic reviews and meta-analysis

\begin{tabular}{|c|c|c|c|c|c|c|c|c|c|c|c|c|c|c|c|c|c|}
\hline \multicolumn{18}{|c|}{ AMSTAR questions* } \\
\hline Authors & 1 & 2 & 3 & 4 & 5 & 6 & 7 & 8 & 9 & 10 & 11 & 12 & 13 & 14 & 15 & 16 & Rating \\
\hline Sriuttha et al. ${ }^{11}$ & $\sqrt{ }$ & $\mathrm{P}$ & $\sqrt{ }$ & $\mathrm{P}$ & $\sqrt{ }$ & $\sqrt{ }$ & - & $\mathrm{P}$ & $\mathrm{P}$ & - & $\mathrm{n} / \mathrm{a}$ & $\mathrm{n} / \mathrm{a}$ & - & - & $\mathrm{n} / \mathrm{a}$ & $\sqrt{ }$ & $\mathrm{CL}$ \\
\hline Nderitu et al. ${ }^{12}$ & $\sqrt{ }$ & $\mathrm{P}$ & $\sqrt{ }$ & $\mathrm{P}$ & $\sqrt{ }$ & $\sqrt{ }$ & - & $\mathrm{P}$ & $\mathrm{P}$ & - & $\sqrt{ }$ & - & $\sqrt{ }$ & $\sqrt{ }$ & $\sqrt{ }$ & $\sqrt{ }$ & $\mathrm{L}$ \\
\hline Zhang et al. ${ }^{13}$ & $\sqrt{ }$ & $\mathrm{P}$ & $\sqrt{ }$ & $\mathrm{P}$ & $\sqrt{ }$ & $\sqrt{ }$ & - & $\mathrm{P}$ & - & - & $\sqrt{ }$ & $\sqrt{ }$ & $\sqrt{ }$ & $\sqrt{ }$ & $\sqrt{ }$ & $\sqrt{ }$ & $\mathrm{L}$ \\
\hline Asghar et al. ${ }^{14}$ & $\sqrt{ }$ & $\mathrm{P}$ & $\sqrt{ }$ & $\mathrm{P}$ & $\sqrt{ }$ & $\sqrt{ }$ & - & $\mathrm{P}$ & - & - & $\mathrm{n} / \mathrm{a}$ & $\mathrm{n} / \mathrm{a}$ & - & $\sqrt{ }$ & $\mathrm{n} / \mathrm{a}$ & $\sqrt{ }$ & $\mathrm{CL}$ \\
\hline Yaxley et al. ${ }^{15}$ & $\sqrt{ }$ & $\mathrm{P}$ & $\sqrt{ }$ & $\mathrm{P}$ & $\sqrt{ }$ & $\sqrt{ }$ & - & $\mathrm{P}$ & - & - & $\mathrm{n} / \mathrm{a}$ & $\mathrm{n} / \mathrm{a}$ & - & - & $\mathrm{n} / \mathrm{a}$ & $\sqrt{ }$ & $\mathrm{CL}$ \\
\hline Villa et al..$^{16}$ & $\sqrt{ }$ & $\mathrm{P}$ & $\sqrt{ }$ & $\mathrm{P}$ & $\sqrt{ }$ & $\sqrt{ }$ & - & $\mathrm{P}$ & - & - & $\mathrm{n} / \mathrm{a}$ & $\mathrm{n} / \mathrm{a}$ & - & - & $\mathrm{n} / \mathrm{a}$ & $\sqrt{ }$ & $\mathrm{CL}$ \\
\hline Ungprasert et al. ${ }^{17}$ & $\sqrt{ }$ & $\mathrm{P}$ & $\sqrt{ }$ & $\mathrm{P}$ & $\sqrt{ }$ & $\sqrt{ }$ & - & $P$ & $\sqrt{ }$ & - & $\sqrt{ }$ & $\sqrt{ }$ & $\sqrt{ }$ & $\sqrt{ }$ & $\sqrt{ }$ & $\sqrt{ }$ & $\mathrm{CL}$ \\
\hline Liu et al. ${ }^{18}$ & $\sqrt{ }$ & $\mathrm{P}$ & $\sqrt{ }$ & $\mathrm{P}$ & $\sqrt{ }$ & $\sqrt{ }$ & - & $\mathrm{P}$ & $\sqrt{ }$ & - & $\sqrt{ }$ & $\sqrt{ }$ & $\sqrt{ }$ & $\sqrt{ }$ & - & $\sqrt{ }$ & $\mathrm{L}$ \\
\hline Seshasai et al. ${ }^{19}$ & $\sqrt{ }$ & $\mathrm{P}$ & $\sqrt{ }$ & $\mathrm{P}$ & $\sqrt{ }$ & $\sqrt{ }$ & - & $\mathrm{P}$ & $\sqrt{ }$ & - & $\sqrt{ }$ & $\sqrt{ }$ & $\sqrt{ }$ & $\sqrt{ }$ & $\sqrt{ }$ & $\sqrt{ }$ & $\mathrm{L}$ \\
\hline Whitlock et al. ${ }^{20}$ & $\sqrt{ }$ & $\mathrm{P}$ & $\sqrt{ }$ & $\mathrm{P}$ & $\sqrt{ }$ & $\sqrt{ }$ & - & $\mathrm{P}$ & - & - & $\mathrm{n} / \mathrm{a}$ & $\mathrm{n} / \mathrm{a}$ & - & - & $\mathrm{n} / \mathrm{a}$ & $\sqrt{ }$ & $\mathrm{CL}$ \\
\hline${\text { Boulakh et } a l^{21}}^{21}$ & $\sqrt{ }$ & $\mathrm{P}$ & $\sqrt{ }$ & $\mathrm{P}$ & $\sqrt{ }$ & $\sqrt{ }$ & - & $\mathrm{P}$ & - & - & $\mathrm{n} / \mathrm{a}$ & $\mathrm{n} / \mathrm{a}$ & - & - & $\mathrm{n} / \mathrm{a}$ & $\sqrt{ }$ & $\mathrm{CL}$ \\
\hline Ungprasert et al. ${ }^{22}$ & $\sqrt{ }$ & $\mathrm{P}$ & $\sqrt{ }$ & $\mathrm{P}$ & $\sqrt{ }$ & $\sqrt{ }$ & - & $\mathrm{P}$ & $\sqrt{ }$ & - & $\sqrt{ }$ & $\sqrt{ }$ & $\sqrt{ }$ & $\sqrt{ }$ & $\sqrt{ }$ & $\sqrt{ }$ & $\mathrm{L}$ \\
\hline $\begin{array}{l}\text { García Rodríguez } \\
\text { et al. }{ }^{23}\end{array}$ & $\sqrt{ }$ & $\mathrm{P}$ & $\sqrt{ }$ & $\mathrm{P}$ & $\sqrt{ }$ & $\sqrt{ }$ & - & $\mathrm{P}$ & - & - & $\mathrm{n} / \mathrm{a}$ & $\mathrm{n} / \mathrm{a}$ & - & $\sqrt{ }$ & $\mathrm{n} / \mathrm{a}$ & $\sqrt{ }$ & $\mathrm{CL}$ \\
\hline Salvo et $a l^{24}$ & $\sqrt{ }$ & $\mathrm{P}$ & $\sqrt{ }$ & $\mathrm{P}$ & $\sqrt{ }$ & $\sqrt{ }$ & - & $\mathrm{P}$ & $\sqrt{ }$ & - & $\mathrm{n} / \mathrm{a}$ & $\mathrm{n} / \mathrm{a}$ & $\sqrt{ }$ & - & - & $\sqrt{ }$ & $\mathrm{L}$ \\
\hline Scott et al. ${ }^{25}$ & $\sqrt{ }$ & $\mathrm{P}$ & $\sqrt{ }$ & $\mathrm{P}$ & $\sqrt{ }$ & $\sqrt{ }$ & - & $\mathrm{P}$ & - & $\sqrt{ }$ & $\sqrt{ }$ & - & - & - & - & $\sqrt{ }$ & $\mathrm{CL}$ \\
\hline $\begin{array}{l}\text { Varas-Lorenzo } \\
\text { et al. }{ }^{26}\end{array}$ & $\sqrt{ }$ & $\mathrm{P}$ & $\sqrt{ }$ & $\mathrm{P}$ & $\sqrt{ }$ & $\sqrt{ }$ & - & $\mathrm{P}$ & $\sqrt{ }$ & - & $\sqrt{ }$ & $\sqrt{ }$ & $\sqrt{ }$ & $\sqrt{ }$ & $\sqrt{ }$ & $\sqrt{ }$ & $\mathrm{L}$ \\
\hline McGettigan et al. ${ }^{27}$ & $\sqrt{ }$ & $\mathrm{P}$ & $\sqrt{ }$ & $\mathrm{P}$ & $\sqrt{ }$ & $\sqrt{ }$ & - & $\mathrm{P}$ & $\sqrt{ }$ & - & $\mathrm{n} / \mathrm{a}$ & $\mathrm{n} / \mathrm{a}$ & $\sqrt{ }$ & $\sqrt{ }$ & $\mathrm{n} / \mathrm{a}$ & $\sqrt{ }$ & $\mathrm{L}$ \\
\hline Mackenzie et al. ${ }^{28}$ & $\sqrt{ }$ & $\mathrm{P}$ & $\sqrt{ }$ & $\mathrm{P}$ & $\sqrt{ }$ & $\sqrt{ }$ & - & $\mathrm{P}$ & $\sqrt{ }$ & - & $\sqrt{ }$ & $\sqrt{ }$ & $\sqrt{ }$ & - & $\sqrt{ }$ & $\sqrt{ }$ & $\mathrm{L}$ \\
\hline Major et al..$^{29}$ & $\sqrt{ }$ & $\mathrm{P}$ & $\sqrt{ }$ & $\mathrm{P}$ & $\sqrt{ }$ & $\sqrt{ }$ & - & $\mathrm{P}$ & $\sqrt{ }$ & - & $\sqrt{ }$ & $\sqrt{ }$ & $\sqrt{ }$ & $\sqrt{ }$ & $\sqrt{ }$ & $\sqrt{ }$ & $\mathrm{L}$ \\
\hline Luni et $a .^{30}$ & $\sqrt{ }$ & $\mathrm{P}$ & $\sqrt{ }$ & $\mathrm{P}$ & $\sqrt{ }$ & $\sqrt{ }$ & - & $\mathrm{P}$ & $\sqrt{ }$ & - & $\sqrt{ }$ & $\sqrt{ }$ & $\sqrt{ }$ & $\sqrt{ }$ & $\sqrt{ }$ & $\sqrt{ }$ & $\mathrm{L}$ \\
\hline Lee et $a l^{31}$ & $\sqrt{ }$ & $\mathrm{P}$ & $\sqrt{ }$ & $\mathrm{P}$ & $\sqrt{ }$ & $\sqrt{ }$ & - & $\mathrm{P}$ & $\sqrt{ }$ & - & $\sqrt{ }$ & $\sqrt{ }$ & - & $\sqrt{ }$ & - & $\sqrt{ }$ & $\mathrm{CL}$ \\
\hline Bem et $a l^{32}$ & $\sqrt{ }$ & $\mathrm{P}$ & $\sqrt{ }$ & $\mathrm{P}$ & $\sqrt{ }$ & $\sqrt{ }$ & - & $\mathrm{P}$ & $\sqrt{ }$ & - & $\mathrm{n} / \mathrm{a}$ & $\mathrm{n} / \mathrm{a}$ & $\sqrt{ }$ & $\mathrm{n} / \mathrm{a}$ & $\sqrt{ }$ & $\sqrt{ }$ & $\mathrm{L}$ \\
\hline
\end{tabular}

*: 1. Did the research questions and inclusion criteria for the review include the components of PICO? 2. Did the report of the review contain an explicit statement that the review methods were established prior to the conduct of the review and did the report justify any significant deviations from the protocol? 3. Did the review authors explain their selection of the study designs for inclusion in the review? 4. Did the review authors use a comprehensive literature search strategy? 5. Did the review authors perform study selection in duplicate? 6. Did the review authors perform data extraction in duplicate? 7. Did the review authors provide a list of excluded studies and justify the exclusions? 8. Did the review authors describe the included studies in adequate detail? 9. Did the review authors use a satisfactory technique for assessing the risk of bias $(\mathrm{RoB})$ in individual studies that were included in the review? 10. Did the review authors report on the sources of funding for the studies included in the review? 11. If meta-analysis was performed did the review authors use appropriate methods for statistical combination of results? 12. If meta-analysis was performed, did the review authors assess the potential impact of RoB in individual studies on the results of the meta-analysis or other evidence synthesis? 13. Did the review authors account for RoB in individual studies when interpreting/ discussing the results of the review? 14. Did the review authors provide a satisfactory explanation for, and discussion of, any heterogeneity observed in the results of the review? 15. If they performed quantitative synthesis did the review authors carry out an adequate investigation of publication bias (small study bias) and discuss its likely impact on the results of the review? 16. Did the review authors report any potential sources of conflict of interest, including any funding they received for conducting the review?

Rating overall confidence: $\mathrm{H}$ (high): zero or one non-critical weakness; M (moderate): more than one non-critical weakness; L (low): one critical flaw with or without non-critical weaknesses; CL (critically low): more than one critical flaw with or without non-critical weaknesses.

$\sqrt{ }$ : yes; P: partial yes; -: no; n/a: not applicable because the study is not a meta-analysis. 


\section{DISCUSSION}

This umbrella review can be a useful tool for offering evidence to physicians in the prescription process considering the different aspects of safety and efficacy of NSAIDs $^{33}$.

IT compiling the evidence from 22 existing reviews and meta-analyses highlights the need for caution when prescribing NSAIDs to patients with prior cardiovascular disease, hypertension, at risk of cirrhosis or kidney disease, and general population. Our review found that the use of NSAIDs was associated with an increased likelihood of cardiovascular events ${ }^{17,18,22,23,25,26,34}$ and cardiovascular risk $^{27}$. The reviewed evidence showed that NSAIDs were associated with cardiovascular side-effects that increase both systolic and diastolic blood pressure and this may precipitate cardiovascular events ${ }^{35-38}$. It is important to underline that the simultaneous use of NSAIDs and antihypertensives can increase blood pressure levels, generating problems of ineffectiveness of antihypertensive treatments in some patients ${ }^{16}$.

On the other hand, a key element that is generating a great debate in the scientific community is the use of aspirin for primary prevention of cardiovascular disease in elderly patients. We have found two SR analysing this issue ${ }^{19,20}$, with varying results. Seshasai et al. ${ }^{19}$ concluded that aspirin treatment reduced total CVD events, driven by reductions in non-fatal myocardial infarction, but no significant reduction was found in CVD death, while Whitlock et $a l .{ }^{20}$ found that an intervention of very lowdose aspirin $(\leq 100 \mathrm{mg}$ daily or every other day) could increase haemorrhagic stroke risk although results were not statistically significant.

Although the association between NSAIDs and kidney damage was not clearly established, except for NSAID at high doses, this potential relationship becomes highly relevant if we take into account the wide use of NSAIDs among our community and the fact that $2 \%$ of the national health budget is spent on renal replacement therapy $^{39}$.
In general, this overview could be affected by the lack of representability. Many of the studies included in this analysis showed increased risks in general populations by assessment of harms in relative terms (RR or OR), with small absolute differences when they were quantified. Data for risk increment in absolute terms in patients previously affected by renal, hepatic or cardiovascular conditions are lacking in some reviewed studies. In these settings with augmented basal risk, it would be reasonable to assume greater absolute risks if relative increases were at least maintained.

Finally, it is believed that the large number of SR included in this umbrella review provided a good estimation of the state of the art of recommendations for prescribing NSAIDs ${ }^{41}$. Moreover, taking into account the results of the analyses, and that the risks are usually minimised, a cautious attitude must be taken.

Our findings are in line with the guidelines recommending avoidance of NSAIDs in patients with cardiovascular disease, chronic kidney disease, hypertension and cirrhosis. Taking into account the different risk profiles of patients and the differences that exist between the drugs, it is necessary to individualize their use based on the type of process for which they are used and the characteristics of the patient ${ }^{42}$. Caution should therefore be taken when recommending or prescribing NSAIDs and patients should be advised about its potential consequences on health. Proper follow-up should be ensured.

The conclusion of this review of reviews is that the prescription of NSAIDs should continue to be done with caution, taking into account the risk of NSAIDs in high-risk patients. This conclusion is in concordance with other international scientific initiatives such as Choosing wisely in the United States $^{43}$, Do not $d o^{44}$ from The National Institute for Health and Care Excellence (NICE) in the United Kingdom and Commitment to the Quality of Scientific Societies ${ }^{45}$ in Spain.

\section{Acknowledgments}

To Camila Higueras, librarian EASP. 


\section{REFERENCES}

1. Loza E. AINEs en la práctica clínica: lo que hay que saber. Inf Ter Sist Nac Salud 2011; 35: 88-95.

2. Ministerio de Sanidad, Servicios Sociales e Igualdad. Gobierno de España. Utilización de medicamentos antiinflamatorios no esteroideos en España durante el periodo 2013-2016. Informe de utilización de medicamentos U/AIN/V1/11/09/2017. https://www. aemps.gob.es/medicamentosUsoHumano/ observatorio/docs/antiinflamatorios-AINEsperiodo-2013-2016.pdf

3. WelsBy PD. WHO analgesic ladder. Treasure Island: StatPearls Publishing 2008; 284.

4. Breivik H, Collett B, Ventafridda V, Cohen R, Gallacher D. Survey of chronic pain in Europe: Prevalence, impact on daily life, and treatment. Eur J Pain 2006; 10: 287-333. https://doi.org/10.1016/j.ejpain.2005.06.009

5. Ubeda A, Ferrándiz ML, Maicas N, Gomez C, BoNET M, PERIS JE. [Potentially inappropriate prescribing in institutionalised older patients in Spain: the STOPP-START criteria compared with the Beers criteria]. Pharm Pract 2012; 10: 83-91 https://doi.org/10.4321/ s1886-36552012000200004

6. Risser A, Donovan D, Heintzman J, Page T. NSAID prescribing precautions. Am Fam Physician 2009; 80: 1371-1378.

7. Smith V, Devane D, Begley CM, Clarke M. Methodology in conducting a systematic review of systematic reviews of healthcare interventions. BMC Med Res Methodol 2011; 11: 1-6. https://doi.org/10.1186/1471-2288-1115

8. Ministerio de Sanidad. Gobierno de España. Red Española de Agencias de Evaluación de Tecnologías Sanitarias y Prestaciones del Sistema Nacional de Salud. https://redets. sanidad.gob.es/

9. Bougioukas KI, Bouras E, Apostolidou-Kiouti F, KokKali S, Arvanitidou M, Haidich A-B. Reporting guidelines on how to write a complete and transparent abstract for overviews of systematic reviews of health care interventions. J Clin Epidemiol 2019; 106: 70-79. https://doi.org/10.1016/j.jclinepi.2018.10.005

10. Shea BJ, Reeves BC, Wells G, Thuku M, Hamel C, Moran J et al. AMSTAR 2: A critical appraisal tool for systematic reviews that include randomised or non-randomised studies of healthcare interventions, or both. BMJ 2017; 358. https://doi.org/10.1136/bmj.j4008
11. Sriuttha P, Sirichanchuen B, Permsuman U. Hepatotoxicity of nonsteroidal anti-inflammatory drugs: a systematic review of randomized controlled trials. Int J Hepatol 2018. https:// doi.org/10.1155/2018/5253623

12. Nderitu P, Doos L, Jones PW, Davies SJ, Kadam UT. Non-steroidal anti-inflammatory drugs and chronic kidney disease progression: A systematic review. Fam Pract 2013; 30: 247-255. https://doi.org/10.1093/fampra/ cms086

13. Zhang X, Donnan PT, Bell S, Guthrie B. Non-steroidal anti-inflammatory drug induced acute kidney injury in the community dwelling general population and people with chronic kidney disease: systematic review and metaanalysis. BMC Nephrol 2017; 18: 256. https:// doi.org/10.1186/s12882-017-0673-8

14. Asghar W, Jamali F. The effect of COX-2-selective meloxicam on the myocardial, vascular and renal risks: a systematic review. Inflammopharmacology 2014; 23: 1-16. https://doi. org/10.1007/s10787-014-0225-9

15. YAXLEY J, LITFIN T. Non-steroidal anti-inflammatories and the development of analgesic nephropathy: a systematic review. Ren Fail 2016; 38: 1328-1334. https://doi.org/10.1080/ 0886022x.2016.1216708

16. Villa J, Cano A, Franco D, Monsalve M, Hincapié J, Amariles P. [Clinical relevance of drug interactions between nonsteroidal antiinflammatory drugs (NSAIDs) and antihypertensives]. Aten Primaria 2014; 46: 464-474 https://doi. org/10.1016/j.aprim.2013.11.010

17. Ungrrasert P, Srivali N, Thongrrayoon C. Nonsteroidal anti-inflammatory drugs and risk of incident heart failure: a systematic review and meta-analysis of observational studies. Clin Cardiol 2016; 39: 111-118. https://doi. org/10.1002/clc.22502

18. Liu G, YAN YP, Zheng XX, Xu YL, Lu J, Hui RT et al. Meta-analysis of nonsteroidal anti-inflammatory drug use and risk of atrial fibrillation. Am J Cardiol 2014; 114: 1523-1529. https:// doi.org/10.1016/j.amjcard.2014.08.015

19. Seshasal SRK, WiJesuriya S, Sivakumaran R, Nethercott S, Erqou S, Sattar N et al. Effect of aspirin on vascular and nonvascular outcomes: meta-analysis of randomized controlled trials. Arch Intern Med 2012; 172: 209-216. https://doi.org/10.1001/archinternmed.2011.628

20. Whitlock EP, Burda BU, Williams SB, GuirguisBLAKE JM, Evans C V. Bleeding risks with aspirin use for primary prevention in adults: a systematic review for the U.S. preventive 
services task force. Ann Intern Med 2016; 164: 826-835. https://doi.org/10.7326/m152112

21. Boulakh L, Gislason GH. Treatment with nonsteroidal anti-inflammatory drugs in patients after myocardial infarction - a systematic review. Expert Opin Pharmacother 2016; 17: 1387-1394. https://doi.org/10.1080/14656566. 2016.1186648

22. Ungprasert P, SRivali N, Kittanamongkolchai W. Non-steroidal anti-inflammatory drugs and risk of heart failure exacerbation: A systematic review and meta-analysis. Eur J Intern Med 2015; 26: 685-690. https://doi. org/10.1016/j.ejim.2015.09.012

23. García Rodríguez LA, GonzÁlez-Pérez A, Bueno $\mathrm{H}$, HwA J. NSAID use selectively increases the risk of non-fatal myocardial infarction: A systematic review of randomised trials and observational studies. PLoS One 2011; 6: e16780. https://doi.org/10.1371/journal. pone.0016780

24. Salvo F, Fourrier-Réglat A, Bazin F, Robinson P, Riera-Guardia N, HAAG M et al. Cardiovascular and gastrointestinal safety of NSAIDs: A systematic review of meta-analyses of randomized clinical trials. Clin Pharmacol Ther 2011; 89: 855-866. https://doi.org/10.1038/ clpt.2011.45

25. Scott PA, KInGsley GH, Scott DL. Non-steroidal anti-inflammatory drugs and cardiac failure: meta-analyses of observational studies and randomised controlled trials. Eur J Heart Fail 2008; 10: 1102-1107. https://doi.org/10.1016/j. ejheart.2008.07.013

26. Varas-Lorenzo C, Riera-Guardia N, Calingaert B, Castellsague J, Salvo F, Nicotra F et al. Myocardial infarction and individual nonsteroidal anti-inflammatory drugs meta-analysis of observational studies. Pharmacoepidemiol Drug Saf 2013; 22: 559-570. https://doi. org/10.1002/pds.3437

27. McGettigan P, Henry D. Cardiovascular risk with non-steroidal anti-inflammatory drugs: Systematic review of population-based controlled observational studies. PLoS Med 2011; 8. https://doi.org/10.1371/journal. pmed.1001098

28. Mackenzie IS, Wei L, MacDonald TM. Cardiovascular safety of lumiracoxib: A meta-analysis of randomised controlled trials in patients with osteoarthritis. Eur J Clin Pharmacol 2013; 69: 133-141. https://doi.org/10.1007/ s00228-012-1335-1

29. Major RW, Oozeerally I, Dawson S, RiddlestON H, GRAY LJ, BRUNSKILL NJ. Aspirin and cardiovascular primary prevention in nonendstage chronic kidney disease: A metaanalysis. Atherosclerosis 2016; 251: 177182. https://doi.org/10.1016/j.atherosclerosis.2016.06.013

30. Luni FK, Riaz H, Khan AR, Riaz T, Husnain M, RIAZ I BIN et al. Clinical outcomes associated with per-operative discontinuation of aspirin in patients with coronary artery disease: A systematic review and meta-analysis. Catheter Cardiovasc Interv 2017; 89: 1168-1175. https://doi.org/10.1002/ccd.26807

31. Lee M, Saver JL, Hong KS, Wu HC, Ovbiagele B. Risk-benefit profile of warfarin versus aspirin in patients with heart failure and sinus rhythm a meta-analysis. Circ Hear Fail 2013; 6: 287-292. https://doi.org/10.1161/circheartfailure.112.971697

32. Bem D, Lordkipanidzé M, Hodgkinson J, Stevens S, BAYLISS S, Moore D et al. The effects of different aspirin dosing frequencies and the timing of aspirin intake in primary and secondary prevention of cardiovascular disease: a systematic review. Clin Pharmacol Ther 2016; 100: 500-512. https://doi.org/10.1002/cpt.438

33. Lanas A, Bentto P, Alonso J, Hernández-Cruz B, Barón-Esquivias G, Perez-Aísa Á et al. [Safe prescription recommendations for non steroidal anti-inflammatory drugs: Consensus document ellaborated by nominated experts of three scientific associations (SER-SECAEG)]. Reumatol Clin 2014; 10: 68-84. https:// doi.org/10.1016/j.reuma.2013.10.004

34. Gislason GH, Køber L, Schjerning Olsen A-M, Lock Hansen M, Torp-Pedersen C, Fosbøl EL et al. NSAIDs are associated with increased risk of atrial fibrillation in patients with prior myocardial infarction: a nationwide study. Eur Hear J Cardiovasc Pharmacother 2015; 1: 107114. https://doi.org/10.1093/ehjcvp/pvv004

35. Jones R, Rubin G, Berenbaum F, Scheiman J. Gastrointestinal and cardiovascular risks of nonsteroidal anti-inflammatory drugs. Am J Med 2008; 121: 464-474. https://doi. org/10.1016/j.amjmed.2008.01.045

36. Pope JE, Anderson JJ, Felson DT. A metaanalysis of the effects of nonsteroidal antiinflammatory drugs on blood pressure. Arch Intern Med 1993; 153: 477-484. https://doi. org/10.1001/archinte.1993.00410040045007

37. Johnson AG, NGuYEn TV, Day RO. Do nonsteroidal anti-inflammatory drugs affect blood pressure? A meta-analysis. Ann Intern Med 1994; 121: 289. https://doi.org/10.7326/00034819-121-4-199408150-00011 
38. Trelle S, Reichenbach S, Wandel S, Hildebrand P, TSChanNEn B, ViLliger PM et al. Cardiovascular safety of non-steroidal anti-inflammatory drugs: network meta-analysis. BMJ 2011; 342: 154. https://doi.org/10.1136/bmj.c7086

39. Howell M, Walker RC, Howard K. Cost Effectiveness of dialysis modalities: a systematic review of economic evaluations. Appl Health Econ Health Policy 2019. https://doi. org/10.1007/s40258-018-00455-2

40. Agúndez JA, Lucena MI, Martínez C, Andrade RJ, Blanca M, Ayuso P et al. Assessment of nonsteroidal anti-inflammatory drug-induced hepatotoxicity. Expert Opin Drug Metab Toxicol 2011; 7: 817-828. https://doi.org/10.1517/ 17425255.2011.574613

41. Pieper D, Buechter R, Jerinic P, Eikermann M. Overviews of reviews often have limited rigor: a systematic review. J Clin Epidemiol 2012; 65: 1267-1273. https://doi.org/10.1016/j. jclinepi.2012.06.015
42. Sostres C, LANAS Á. [Appropriate prescription, adherence and safety of non-steroidal anti-inflammatory drugs]. Med Clin 2016; 146: 267-272. https://doi.org/10.1016/j.medcli.2015.09.022

43. BRody H. Promoting conversations between providers and patients. ABIM Foundation. Choosing Wisely 2012. http://www.choosingwisely.org/

44. National Institute for Health and Care Excellence. NICE “do not do" recommendations. https://www.nice.org.uk/about/what-we-do/ our-programmes/nice-guidance/nice-guidelines

45. Ministerio de Sanidad, Consumo y Bienestar Social. Compromiso por la calidad de las Sociedades Científicas en España. Implementación de las recomendaciones de "No Hacer". 2018. https://www.mscbs.gob.es/organizacion/sns/planCalidadSNS/cal_sscc.htm 


\section{APPENDIX 1. Search strategy for Medline and Embase}

1. exp Inappropriate Prescribing/ OR exp Potentially Inappropriate Medication List/

2. deprescri*.tw,kw.

3. withdraw*.tw,kw.

4. ceas* ${ }^{*} \mathrm{tw}, \mathrm{kw}$.

5. cessation.tw,kw.

6. discontinu*.tw,kw.

7. [(non indicated OR nonindicated OR inap-

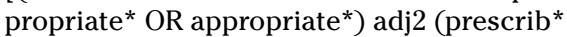
OR prescription* OR "use")].tw,kw.

8. 1 OR 2 OR 3 OR 4 OR 5 OR 6 OR 7

9. *Anti-Inflammatory Agents, Non-Steroidal/

10. ("Anti-Inflammatory Agents, Non-Steroidal" or "Nonsteroidal anti-inflammatory drugs" OR nsaid).ab,ti.

11. 9 OR 10

12. cardiovascular disease.mp. OR Cardiovascular Diseases/

13. *HYPERTENSION/ OR hypertension.mp.

14. Renal Insufficiency, Chronic.mp. OR Renal Insufficiency, Chronic/

15. hepatic cirrhosis.mp. OR Liver Cirrhosis/

16. heart failure.mp. OR Heart Failure/

17. chronic renal failure.mp. OR Kidney Failure, Chronic/

18. 12 OR 13 OR 14 OR 15 OR 16 OR 17

19. 8 AND 11 AND 18

20. Randomized Controlled Trials as Topic/

21. randomizedcontrolled trial/

22. RandomAllocation/

23. DoubleBlindMethod/

24. Single BlindMethod/

25. clinical trial/

26. clinical trial, phase i.pt.

27. clinical trial, phase ii.pt.

28. clinical trial, phase iii.pt.

29. clinical trial, phase iv.pt.

30. controlledclinical trial.pt.

31. randomizedcontrolled trial.pt.

32. multicenter study.pt.

33. clinical trial.pt.

34. exp Clinical Trials as topic/

35. OR/20-34

36. (clinicaladj trial\$).tw.

37. [(singl\$ OR doubl\$ OR treb\$ OR tripl\$) adj (blind $\$ 3$ OR mask\$3)].tw.

38. PLACEBOS/

39. placebo\$.tw.

40. randomly allocated.tw.
41. (allocated adj2 random\$).tw.

42. $\mathrm{OR} / 36-41$

43. 35 OR 42

44. case report.tw.

45. letter/

46. historicalarticle/

47. $\mathrm{OR} / 44-46$

48. 43 NOT 47

49. Meta-Analysis as Topic/

50. meta analy $\$$.tw.

51. metaanaly $\$ . t w$.

52. Meta-Analysis/

53. [systematic adj (review $\$ 1$ or overview $\$ 1)$ ]. tw.

54. exp Review Literature as Topic/

55. OR/49-54

56. cochrane.ab.

57. embase.ab.

58. (psychlitorpsyclit).ab.

59. (psychinfoorpsycinfo).ab.

60. (cinahlorcinhal).ab.

61. sciencecitationindex.ab.

62. bids.ab.

63. cancerlit.ab.

64. $\mathrm{OR} / 56-63$

65. referencelist $\$$.ab.

66. bibliograph $\$$.ab.

67. hand-search $\$ . a b$.

68. relevantjournals.ab.

69. manual search\$.ab.

70. $\mathrm{OR} / 65-69$

71. selectioncriteria.ab

72. data extraction.ab.

73. 71 OR 72

74. Review/

75. 73 AND 74

76. Comment/

77. Letter/

78. Editorial/

79. animal/

80. human/

81. 79 NOT (79 and 80 )

82. OR/76-78,81

83. 55 OR 64 OR 70 OR 75

84. 83 NOT 82

85. 19 AND 48

86. 19 AND 84

87. 85 OR 86 


\section{APPENDIX 2. Investigation stages and methods for umbrella review}

\begin{tabular}{|c|c|c|c|}
\hline Step & Purpose & Activities & $\begin{array}{c}\text { Responsible } \\
\text { authors }\end{array}$ \\
\hline 1 & $\begin{array}{l}\text { Determining } \\
\text { the research } \\
\text { question }\end{array}$ & $\begin{array}{l}\text { Several meetings were held in order to agree on the definitions and ob- } \\
\text { jectives of this review. Based on the literature, key search terms and } \\
\text { possible literature sources were identified. First of all, and taking into } \\
\text { account search results and the objectives of this study, we decided that } \\
\text { the ideal method for summarising evidence was to make an umbrella } \\
\text { review. }\end{array}$ & $\begin{array}{l}\text { AOL, CBT, } \\
\text { AMH, EAR, } \\
\text { ESF and } \\
\text { independent } \\
\text { staff }^{*}\end{array}$ \\
\hline 2 & $\begin{array}{l}\text { Identification } \\
\text { of relevant } \\
\text { studies }\end{array}$ & $\begin{array}{l}\text { The preliminary criteria for including and excluding studies were de- } \\
\text { veloped and reviewed iteratively. To maximise search sensitivity, two } \\
\text { searches were carried out in parallel, with and without review filter } \\
\text { (SIGN). The literature search was complemented by other databases } \\
\text { and grey literature, and was finished on } 1^{\text {st }} \text { july using Mendeley refer- } \\
\text { ence management software. }\end{array}$ & $\begin{array}{l}\text { AOL, CBT and } \\
\text { ESF }\end{array}$ \\
\hline 3 & $\begin{array}{l}\text { Selection of } \\
\text { studies }\end{array}$ & $\begin{array}{l}\text { Titles and abstracts were reviewed independently, taking into account } \\
\text { the pre-determined inclusion and exclusion criteria. Then the full texts } \\
\text { of articles which were relevant to the study objectives were reviewed, } \\
\text { and any disagreements solved by a third reviewer. }\end{array}$ & $\begin{array}{l}\text { AOL, CBT and } \\
\text { ESF }\end{array}$ \\
\hline 4 & $\begin{array}{l}\text { Data extraction } \\
\text { and analysis }\end{array}$ & $\begin{array}{l}\text { Data extraction was done on a consensus basis. Then an independent } \\
\text { person checked that the information extracted was complete and pre- } \\
\text { cise. Information obtained from identified studies was then categorised, } \\
\text { and subsequently the paper was drafted. }\end{array}$ & AOL and ESF \\
\hline 5 & $\begin{array}{l}\text { Participation } \\
\text { of interested } \\
\text { parties }\end{array}$ & $\begin{array}{l}\text { The results of this review form part of a larger project being carried out } \\
\text { on "do not" recommendations based on scientific evidence. An in-depth } \\
\text { analysis using mixed methods is also being carried out. }\end{array}$ & $\begin{array}{l}\text { The entire } \\
\text { team }\end{array}$ \\
\hline
\end{tabular}

*The search strategy was checked by a librarian with wide experience in the public health field. 
